\title{
Türkiye Tiyatrosunda Romantik Karakterler
}

\author{
Romantic Characters in Turkish Theatre
}

Beliz Güçbilmez*

ÖZET

Romantizmin Türk tiyatrosunda belirgin bir karsiligi olmamasina ragmen, belirli bir “romantik kahraman” olgusundan söz etmek mümkündür. Özellikle de çagdas oyun yazarliginda karsilasilan bu yaratim, genellikle romantik sanatin ve düsünün, an'dan kaçma, oyun, öz-farkindalik gibi asal belirleyenlerine basvurmustur. Bu makale, bu tür bir karakter yaratma egiliminin izlerini Oguz Atay'in Oyunlarla Yasayanlar. Memed Baydur'un Limon, Sabahattin Kudret Aksal Bay Hic ve Sonsuzluk Kitabevi adli oyunlarinda aramaktadir.

\begin{abstract}
Though it is quite difficult to find a direct influence of European Romanticism on Turkish theatre, it is possible to consider a contemporary trend of creating "romantic hero". This tendency in contemporary Turkish theatre makes use of the fundamental characteristics of romantic thought such as escapism, romantic game and self-awareness. This article aims to search for these characteristics in Oguz Atay's, Oyunlarla Yasayanlar, Memed Baydur's Limon, Sabahattin Kudret Aksal's Bay Hiç and Sonsuzluk Kitabevi texts.
\end{abstract}

Türk tiyatrosunda romantizmin kendi tarihsel süreci içinde düsünsel etkileri olmussa da, özellikle Alman romantik kuramcilarinin sanat yapitina iliskin yaklasimlarinin karsiligini bulmak pek mümkün görünmemektedir. Buna ragmen Türkiye tiyatro yazininda belirgin bir "romantik kahraman" damari oldugu görülebilmektedir. $\mathrm{Bu}$ yazinin genel çerçevesi, kimi çagdas oyun yazarlarinin yarattiklari karakterlerin/tiplerin romantik felsefeden devraldiklari niteliklerle kendilerini ortak bir kategoriye yerlestirme biçimlerine odaklidir. Romantik felsefenin üç asal niteligi olan "an'dan kaçma", "bilincin belirledigi bir öz-farkindalik hali” ve "oyun", bu çerçevede yaratilmis oyun kisilerini ayni niteliklerle donatir. Oyunlarla

* Ögretim Görevlisi Dr. A.Ü. Dil ve Tarih-Cografya Fakültesi Tiyatro Bölümü 
$\underline{\text { Yasayanlar }}^{1}, \underline{\text { Limon }}^{2}, \underline{\text { Bay Hic }}^{3}, \underline{\text { Sonsuzluk Kitabevi }}{ }^{4}$, oyunlarindaki eksen kisiler “romantik kahraman”lik niteliklerini büyük ölçüde barindirmaktadir.

\section{An'dan kaçma/zamani asma}

Yukarida sayilan oyunlarin kahramanlarinin tümü de "aydin"dir; farkindalikla yasama "talihsizligi" içindedirler.Ne sistemin disina çikabilirler ne de bir parçasi olabilirler. Varlik kanallari daralmistir. Gündelik yasamin kalin duvarlari arasinda sikisan bu romantik aydin oyun kisileri, hem oynadiklari oyunlarla zamani ve uzami kendilerince yeniden yaratip dönüstürme, hem de daha çok bir baska zamanda -ileride ya da geride- yasama ihtiyaci içindedirler. Bu nedenle hepsi de "an”dan kaçarlar.

“Romantiklik simdi'den bir kaçistir, geçmise, gelecege, baska

bir evrene ya da çogunlukla ne idügü belirsiz bir sise kaçistir.

(...)Romantiklik Burasi ile Simdi'nin kiskacindan kurtulmayi özler. ${ }^{5}$

Walter Kaufmann'in yukarida aktarilan sözleri, tiyatroda romantizm açisindan daha belirgin bir imkansizliga isaret etmektedir. Tanimi geregi her zaman simdi'yi ve burada'yi gösteren tiyatro sanatinin araçlariyla romantizmin akil yürütmeleri bir araya geldiginde ilginç sonuçlar çikacagi önceden kestirilebilir. Ancak romantizm'in salt simdi'den kaçisa indirgenemeyecegini de belirtmekte yarar vardir. Animsamanin toplumsal olan tarafindan bastirilan ögeleri geri getirmenin bir araci oldugunu söyleyen Herbert Marcuse,

Yeniden ortaya çikarilan geçmis, bugünün tabulastirdigi dönüm noktalarini ortaya koyar. Üstelik bellegin tazelenmesi, hayalin (fantezinin) idrak içeriginin de tazelenmesine yol açar. ${ }^{6}$

derken, animsama eyleminin, günün kisitlanmisligininin ayirdina varilmasini sagladigini söyler. Geçmisle gelecek arasindaki bag, düsünüldügünden de saglamdir.

\footnotetext{
${ }^{1}$ Oguz Atay, Oyunlarla Yasayanlar, (Istanbul: Iletisimm Yayinlari, 1993).

2 Memed Baydur, Limon (Istanbul: Boyut Yayinlari, 1993).

${ }^{3}$ Sabahattin Kudret Aksal, Bay Hic (Istanbul: Cem Yayinevi, 1991).

4 ______ Sonsuzluk Kitabevi (Istanbul: Cem Yayinevi, 1991).

5 Walter Kaufmann, Dostoyevski'den Sartre'a Varolusçuluk, Çev.: Aksit Göktürk (Istanbul: de Yayinevi, 1965), s. 8.

${ }^{6}$ Herbert Marcuse, Eros ve Uygarlik, Çev.: S. Çagan (Istanbul: May Yayinlari, 1968), s.35.
} 
Geçmise yönelme, gelecege yönelme egilimi gösterir. 'Recherche du temps perdu' (geçmisin arastirilmasi/"yitik zaman pesinde”), gelecegin erkinligi için bir araç durumuna gelir. ${ }^{1}$ (vurgulu ek bana ait)

Romantik olusun salt sorumsuzca an'dan kaçma anlamina gelemeyeceginin açik bir göstergesi olan bu sözler, verili zamani asarak, yeniden yaratilmis, sanal bir zaman akisi içinde örgütlenen yasantilarin, özünde gelecekçi bir egilim tasidigini kesinler. "Kaçak" bir tutumdan çok "elestirel" bir konumdan söz etmek daha dogru gibi görünmektedir. Verili an'in ya da "su an”in disinda kalmaya yönelik egilimin/çabanin, nostalji olarak degerlendirilebilecek bir yönelim gösterdigi durumlarda bu gelecekçilik ya da simdi bagimliligi kendini daha da belirgin bir biçimde ortaya koyar. "Eve dönüs" (nostos) ve "aci" (algos) sözcüklerinin Yunanca'sindan türetilmis bir sözcük, olan nostalji, kendi evrimi içinde, mekana iliskin içerimlerini neredeyse tamamen yitirerek zamana iliskin bir imayi güçlü bir sekilde barindirmaya baslamistir. Ancak zaman, mekandan farkli olarak, içinden bir kez çikildiginda, bir daha dönülemeyendir. Üstelik dönülmek istenip de dönülemeyen geçmisin aslinda tam olarak yasanmis geçmis oldugu söylenemez. Düslendigi, hayal edildigi biçimiyle geçmise dönme istegi olarak tanimlanabilecek nostalji bu anlamda geçmisten çok simdi ile ilgilidir. Yani Bakhtin'in "tarihsel ters yüz etme" dedigi süreç islemektedir; bugün yasanmayan bir ideal geçmise yansitilmaktadir. ${ }^{2} \mathrm{Bu}$ çerçeveden bakildiginda nostaljinin geçmise dair içerimlerine ragmen, daha çok simdi ile ilgili olmasi, dahasi kurulumu için simdi'nin negatif türevine bagli bir formülasyona ihtiyaç duyuluyor olmasi, nostaljinin, simdi'nin bir fonksiyonu ve baslibasina elestirel bir konum olarak algilanmasini mümkün kilar. Nostaljinin asal eylem biçimi olan animsama da bu noktadan bakildiginda, bir yeniden yaratma, yeniden kurma imasi tasimasi nedeniyle, kendi karsiti olan unutmayi da içinde barindirir. Geçmisin simdi'de yasanmayan idealleri içeren bir dönem haline gelebilmesi için, geçmisin kötü yanlarinin unutulmasi zorunludur.

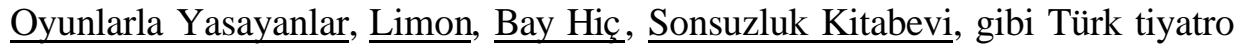
yazininin önemli yapitlari, içerdikleri oyun kisileri ile tiyatro sanatinin dogal zamansal

\footnotetext{
${ }^{1}$ Ayni, s.36.

2 M.M.Bakhtin, The Dialogic Imagination: Four Essays. Ed.: Michael Holquist, Çev.: Carly Emerson ve Michael Holquist (Austin: University of Texas Press, 1981), s.147.
} 
çerçevesi olan sürekli simdi'nin disina kaçmaya çabalamakta, kaçtiklari ara zamanda ve bu zamanla belirlenen "ara gerçeklik"te "oyun"lar kurarak yasamaktadirlar. Bu, romantiklerin yasami estetize ederek kendilerini özgürlestirme yönelimlerinin somutlanisidir aslinda. Bu seçimleri ile her biri "romantik karakter" kütügüne yazilmayi "hak ederler".

Bu oyunlarda karsilasilan "zamani asan romantik" karakterler bir yandan dünyanin her yerindeki benzerleriyle ortak bir "yazgi"yi paylasirlar. Aydin oyun kisileri olarak yaratilmis olmalari, onlari içinde yasadiklari toplumun/dünyanin sorunlarina duyarli kilmis, yasadiklari an'i daha derinden kavrayislari, yogun an'dan kaçma isteklerini öncelemis ya da onlara eslik etmistir. Sonsuzluk Kitabevi ve Bay Hiç'in, aydin kisilerinin ulusal kimliklerinin alti çizilmemistir. Bu kisilerin sorunlari Türkiyeli bir aydinin sorunlarini da kapsar biçimde, dünyanin her hangi bir cografyasinda yasanabilir türdendir. Öte yandan, Oyunlarla Yasayanlar, Limon oyunlarindaki kahramanlarin, aydinlarin yalnizlik ve yabancilasma gibi evrensel sorunlarini da içeren, ancak çogu kez sorunlari özellestirerek ve yerellestirerek yaratilislari dikkat çeker. Bu oyunlarda, fonu, bir türlü demokratiklesemeyen Türkiye olusturmaktadir. Bu durum Türkiye'deki aydinlar açisindan da son derece yogun bir yalnizligi ve yabancilasmayi kaçinilmaz kilmistir. Hepsi de hep bir büyük boguntuyu disa vurmaktadirlar. Boguntularinin kaynagi genelde varoluslari özelde bu kosullarda varoluslari ile ilgili duyduklari sikintilardir. $\mathrm{Bu}$ sikintilar, aydin kahramanlarin edindikleri bilginin sonucu olarak "farkina varma"larindan kaynaklanmaktadir. Geldikleri noktada, ne olduklarina ya da neye dönüstüklerine iliskin rahatsizliklari, onlari, kendilerini çevreleyen gerçekligi, prizmabrindan geçirip, isteklerine göre egip büktükten sonra algilama noktasina getirmistir. Ama sahip olduklari yüksek bilinç düzeyi, kendilerine oynadiklari bu oyunla rahatlamalarina, tümüyle oyunun içinde akip gitmelerine engel olmaktadir. Bir yanlariyla "gerçek hayat"in içindedirler ve günlük yasam onlarin yaralarinin kabuk baglamasina asla izin vermemektedir. Maddi kosullar hep ötekilerden yanadir.

$\mathrm{Bu}$ aydin kahramanlarin en temel ortakliklari, günlük yasamdaki basarisizliklaridir. $\mathrm{Bu}$ acemilik hali, onlari sürekli olarak günlük yasamin bogucu temposundan sikayet etme noktasina getirmistir.

Sabahattin Kudret Aksal'in Sonsuzluk Kitabevinde Adam, benzerleri gibi günlük yasamdan yorgun düsmüstür. 'Çalismak zorunda olus', Freud'un saptadigi gibi mutsuzluklari büyüterek yüzeye çikarmaktadir. 


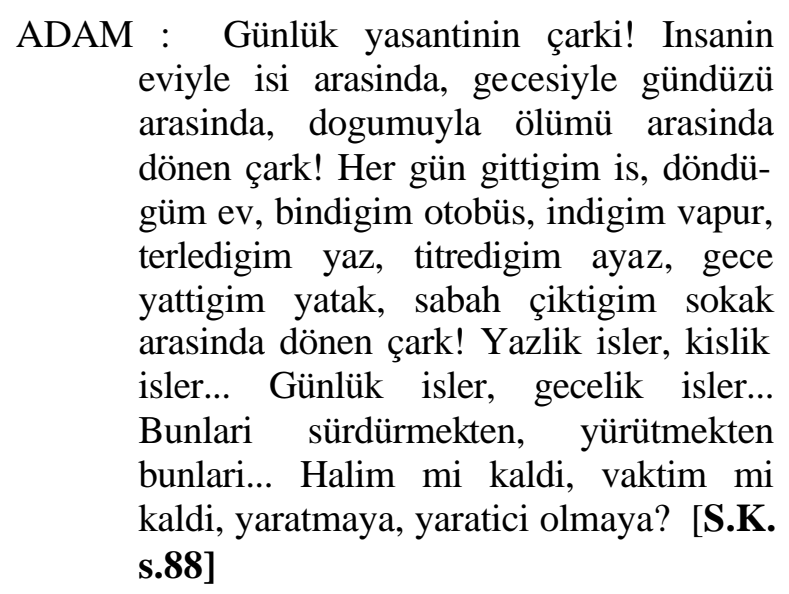

Sonsuzluk Kitabevi adli oyunda Adam yasami boyunca istemedigi islerde çalismis ve elde ettigi bütün parayi yasamindaki en önemli hedefi için saklamistir. Bütün "soy" yapitlari satin alarak, imzalamak ve her birini içerdigi bildiriyle birlikte dostlarina, bütün insanliga göndermektir hedefi. Soy yapitlari tanimlayisi, onun bu hedefini anlamak açisindan önemlidir.

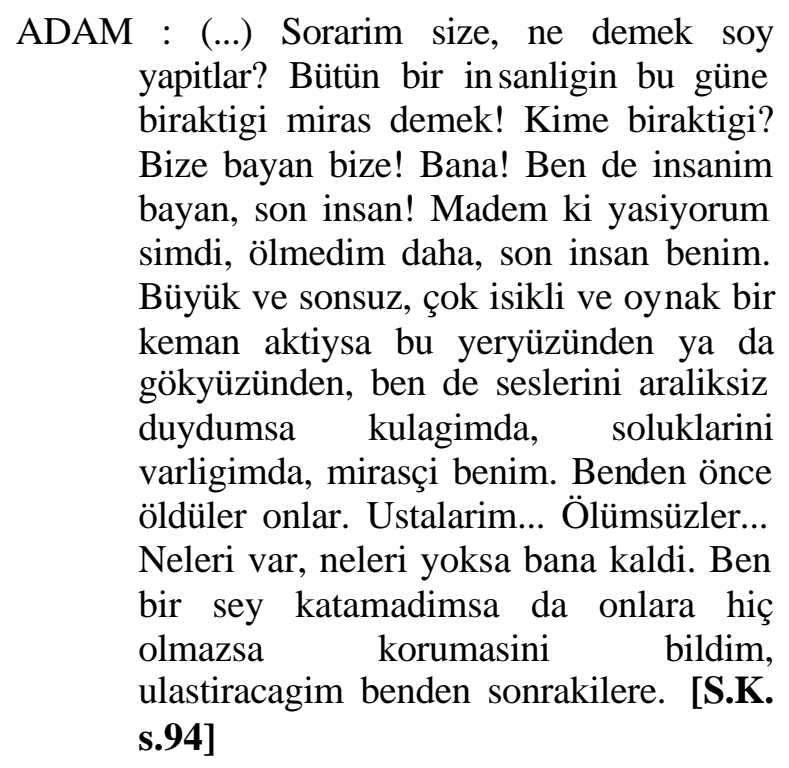

Sürdürülmek istenen ile, sürdürülen yasam arasindaki genis açi, aydini yipratmakta, giderek savrulusunu hazirlamaktadir. Zamansizlik, aydinin kendinden memnun kalacagi alanlarda gelismesini engellemekte, kendinden hosnut olmama ise sürekli huzursuzluklarinin kaynagi olmaktadir. Bu nedenle zamana 'düsman'dir bu aydinlar. Sonsuzluk Kitabevi'nde zaman, bir türlü yakalanamayan ve ölümsüzlüge ulasilarak dize getirilmeye çalisilandir.

Zamani hep azdir Adam'in. Durmaksizin acele etmelerini, pek az zamani kaldigini söyler iki tezgahtar kiza. Zamanin ayriminda olmamakla, zamani sürekli duyumsamak arasinda, zamanla kurulan iliski bakimindan pek bir fark yoktur aslinda. 
Ikisi de ayni çizginin iki farkli ucudur ve bu iki marjinal uç, sonuçta ayni noktada bulusmaktadir. Adam'in zamani gerçekten de kisadir. Oyunun sonuna dogru, kitaplari imzalayacak gücü bile kalmamistir Adam'in. Salt insanlara gönderilme lerini saglamaya çalismaktadir. Son sözleri Goethe'ninkiyle ayni olacaktir:

ADAM : Daha çok aydinlik istiyorum, daha çok aydinlik! (yavasça) Goethe. [S.K.s.104]

Adam, kendine biçtigi bu zamanlar üsẗ̈ romantik misyonu tamamlar tamamlamaz ölecektir. Ölümüyle birlikte, yasami boyunca kendisini yok sayan insanlik onu bastaci edecek, gerçeklestirmek için bir anlamda hayatini ortaya koydugu misyonu karsiligini bulacaktir, ancak salt kendisi açisindan. Evet artik heykelleri dikilen, ödülleri olan biridir ancak dünya, onun geride biraktigindan daha "aydinlik" olmayacaktir. Kendi ölümsüzlügünü saglamis, -hatta kitaplar için ödedigi servet düsünüldügünde ölümsüzlügü satin aldigi da söylenebilir- ancak insanlik adina bir sey yapamamistir. Aydin bu anlamda önüne koydugu romantik hedeflerle salt kendini olmak istedigi insan haline getirmekte, ancak bu degisim yasami dönüstürmek açisindan bir anlam tasimamaktadir.

Sabahattin Kudret Aksal'in baska bir oyunu olan Bay Hiç 'teki Adam da günlük yasamin tüketiciligini disardan gelen kokularla hissetmektedir.

ADAM :Çürümüs sebzelerin, yemislerin, otlarin... Ne bileyim?.. Çürümüs baliklarin, salyangozlarin, kertenkelelerin, pirelerin, tahtakurularinin, bitlerin! Haziranlarin, temmuzlarin, agustoslarin kokusu. (...) Genzim yaniyor. [B.H.s.26]

Bay Hiç amaçsiz degildir. Hatta neredeyse kutsal bir amaci vardir. Bu açidan da Oyunlarla Yasayanlar' in kahramani Coskun Ermis'le çok net bir benzerlikleri vardir. Uzaktan penceresindeki isigi izlerken, Kadin'in kendisine sunacagini umdugu safligi, bir tabula rasa'ya benzeten Erkek neler yapabilecegini anlatir. Kadinin bilincini ve bellegini yeniden yaratirken, bütün bir insanliginkini degistirebilme umudunu gizler gibidir.

ADAM : (...) Ben o bombos levhaya neler, neler, neler... bütün bir uygarlik tarihini, geçmisten çözümlemeler, gele cekten bildiriler... Oyunlar, öyküler, siirler... yiginla betikler yazacaktim. (...) Resimler çizecektim, daha bulunmamis renklerle hem de. Belki de yontular yapardim büyüklü küçüklü. (...) Bir 
dansçi olacak, dans edecektim orada... Bir elimi yildizlara atacaktim, ayaklarim kimi kez yerde, kimi kez havalarda en görülmemis, bugüne degin var olmamis biçimlerde dans edecektim. (...) Yeryüzünün yaratilisi diye bagiracaktim anlamayanlara, yeryüzünün yaratilisi bu iste! Ya da yeryüzünün sonu! [B.H., s.42]

Adam'in zamanla iliskisi kopmustur. Bambaska bir takvimle "bu zamanin" disinda yasar gibidir.

\section{ADAM : Bu gece var mi, ya da yok mu bilmiyorum ki ben. [B.H.s.32]}

Bilinen, yasanan zamanin çok disinda bir yerlerde durur gibidir. Romantikliginin kaynagini da buradan alir.

Memed Baydur'un Limon adli oyunda, entelektüel bir kimlige sahip bir kaç tutunamayanin, alkole ve birbirlerine tutunarak ayakta kalmaya çalistigi görülür. Gelinen noktada yapilabilecek hiç birsey yoktur artik. Yasam, Kafkaesk denebilecek sasirtmayan korkunçluguyla olagan akip gitmekte ve Limon'un kahramanlari durmaksizin içmektedir.

MUHSIN: Sabah oluyor, ögleye dogru, ögle derken ögleden sonra oluyor mu sana aksamüstü, canim aksamüstü, aksam gece filan bir de bakiyoruz gece yarisi, yari gece, yari insan sabaha karsi sabah oluyor... Yeniden basliyoruz... Hep içiyoruz. Içmesek duramayacagiz sanki buralarda. Içerek gic ir gicir nedenler icad ediyoruz kalmak için.... sonunda ne kalmis oluyoruz ne de gitmis... ikisinin ortasinda bir yerde içip duruyoruz.[L.,s.73]

Yasam ve ötekiler, Muhsin, Aziz ve digerleri için yine olabildigince hoyrat ve acimasizdir.

MUHSIN : Bize biyik altindan, burun kivrimindan, göz ucundan, kulak arkasindan gülümseniyor... Biz de vaziyetten istifade edip, bütün saçmalama tahville rini ucuza kapattik. Ne yapsak gülümsüyorlar... Tatli tatli gülümsüyorlar. Aralarinda anlayisli bakislarla sirtimizi sivazlayanlari bile çikiyor. Biz de ha babam, de babam saçmalamaya çalisiyoruz. [L., s. 73] 
Memed Baydur'un, diger oyunlarinda oldugu gibi Limon adli oyununda da oyun kisileri, sikiyönetim döneminin içine kapadigi, renklerini soluklastirdigi, sinmis kahramanlardir. 20. yüzyilin bireyi yokeden hizli çarkina, bu topraklarda örgütlü devlet baskisinin dislileri eklenmistir. Memed Baydur'un oyun kisileri, bir yaniyla son derece evrensel bir kimlik tasirken, bir yaniyla da devlet zorunun gündemde oldugu, göreli bir demokratiklesme sürecini bile tamamlayamamis cografyalarin dar ve kistirilmis yasamlarinin bas kisisidir.

Oguz Atay'in Oyunlarla Yasayanlar adli oyununun kahramani Coskun Ermis, benzer sekilde onu çevreleyen kosullar, gündelik yasam ve buna bagli zorunluluklardan bunalmis bir aydindir. Asil yasamak istedigi ile yasadigi arasindaki uçurum onu mutsuz etmektedir. Genellikle kosullarini yok sayarak yasamaya çalismasina karsin, kendine karsi samimi oldugu anlar vardir:

COSKUN : Hiç utanmadan, sanki hiç
ölmemisim gibi, eve gelenlere hos
geldiniz diyorum, giderlerken güle güle
diyorum. Ve sanki karim dikis
dikmiyormus gibi, sanki eski borçlarim
yüzünden ikide birde kapim
asindirilmiyormus gibi, sanki insanmisim
gibi, yine buyru bekleriz diyorum. "

\section{[O.Y.s.53]}

Oguz Atay'in Oyunlarla Yasayanlar adli oyunu, sadece romantik kahramaninin bireysel kosullarini degil, ülkenin içinde bulundugu olumsuz kosullarin da kokusunu ve izini tasir. Aydinlarin sik sik gözaltina alindigi; hüküm giydigi bir ülkedir içinde yasanilan.

\section{(Coskun Saffet'ten ürkmüs gibi kapiyi hemen onun yüzüne kapar ve telasla kütüphanesine kosar ve bu arada kemani elinden düsürür.(...) Coskun telasla bazi kitaplari raflardan çikarmaya baslar.) \\ COSKUN : (saskin duran keman hocasina) Simdi sanat düsünecek sira degil üstat, baskin var baskin! \\ MÜZIK HOCASI: (anlamadan) Ne baskini? \\ COSKUN: (raflardan çikardigi kitaplari Müzik Hocasi'na verir) Aydin baskini? \\ MÜZIK HOCASI : Ha o baskin mi? [O.Y., s.30]}

Ne eylemlilik adina, ne de "tehlikeli" düsünce adina hiç birsey yapmamis olan Coskun'un bu sekilde gözaltina alinma korkusu akildisidir. Ama gelinen noktada yargi ve hukuk sistemi çöktügü için bu akildisilik günlük hayatin bir parçasi haline gelmis, 
herkes için yasanabilir bir olay olmustur. Korku aydini kendi olmaktan çikarmis, kendi gözünde bile hiç olmadigi denli yasadisi kilmistir.

Özellikle Oyunlarla Yasayanlar metninde eksen kisi olmadigi halde an'dan kaçma meselesinin kavranmasi açisindan son derece doyurucu bir örnek olan Saadet Nine, Coskun Ermis' in konumunun anlasilabilmesini de saglamaktadir. Saadet Nine yasi nedeniyle artik sik sik nerede oldugunu unutmakta, geçmiste yasadigi "parlak" günlerin anisini yasamaktadir. Kendine zaman olarak geçmis'i seçmistir ve geçmis’i yasantilarken yansittigi mutluluk, bugünkü kosullari ve miutsuzlugu ile karsilastirildiginda elestirel bir bakis açisi getirmektedir. Saadet Nine bir oyun kisisi olarak Coskun Ermis'in paraleline yerlestirilmistir. Coskun Ermis'in oyunlara kaçmasi ile Saadet Nine'nin geçmise kaçmasi arasinda bir kosutluk kurulmus, böylece an'dan kaçmanin ya da zamani asmanin iki ayri yöntemi sergilenmistir.

Buraya kadar gösterildigi gibi üzerinde durulan oyunlarin eksen kisilerinin her biri, bir yandan bilenmis duyarliliklari nedeniyle varolus sikintilari çekmekte, bir yandan da geliskin bakis açilari ve degerlendirme yetenekleri ile içinde bulunduklari somut, maddi kosullardan kaçmayi arzu etmektedirler. Toplumsal fon özellikle belirgin kilindiginda bu oyun kisilerinin neden an'dan kaçmak istediklerini kavramak da kolaylasmaktadir.

\section{Romantik öz-farkindalik}

Sanat yapitini temsil edilemez olanin temsili olarak tarifleyen; bir anlamda "imkansizlik"i bir olanak olarak sanatsal yarati formülasyonlarinin içine yerlestiren Schlegel, bu tutumuyla sanatçinin yaraticiliginin da sinirsizligina isaret etmis oluyordu. Ancak sanatçi, sinirlari sanatsal yarati ile asmaya çabalarken de insanin fiziksel sinirliliklarina hapsedilmis oldugunun ayirdindadir ${ }^{1}$. Dolayisiyla bir tür imkansizlik bilincine ragmen (yaratici) insanin sinirlarini zorlamasi konu edilmektedir. Bu hem bilme, hem bilmezden gelme hali, romantik düsüncenin ve onun temsil edilememis temsili olarak kabul edilebilecek romantik sanatin asal öz-farkindalik ilkesinde açiga çikmaktadir. Özne, öznelik ve nesnelik konumlarini ayni anda isgal etmekte, kendisi kalarak kendine disardan bakmayi hedeflemektedir.

Kalici bir yetersizlik itirafi... insanligin kendini yansitan yapitlar üretmekte bosu bosuna israr 
etmediginin, bu ruhla, kavrama becerisinin zaaflarinin ötesine geçtiginin en önemli kanitidir. ${ }^{2}$

Bu bakis açisina göre edebiyat alanindaki her çaba, yaraticisinin kusursuz olmayisiyla sinirlanmis bir çabadir. Ancak bu sinirliliklarin kabul ya da itiraf edilmesi öz-bilinçlilik dolayimiyla sanat yapitina yansiyarak, (ya da sanat yapitinda temsil edilerek) hem yapiti hem sanatçiyi özgürlestirir. Romantik sanatin bütün araçlariyla yakalamaya çalistigi hedefi, bu anlamda "insanligi, evrendeki her seyden kurtarip özgürce yükseklerde uçurmaktir." 3

Türkiye tiyatro yazini düsünüldügünde, bu romantik yaratma egilimini temsil eden ya da animsatan oyunlar bulmak pek de mümkün görünmemektedir. Romantizmden dogrudan etkilenmis gibi görünen oyun yazarlarinin bile melodram formunu örnek almak disinda romantizmin asal düsünsel kategorileri ile bir baglantilari oldugunu savlamak güçtür. Ancak yazilan oyunlarin formunu belirleyecek bir estetik yönelim olarak degilse de, oyun kisisi yaratiminda bir romantik kahraman, hatta giderek romantik "aydin" kahraman kategorisinden söz etmek Türkiye tiyatrosunun geneli için de dogru olacaktir.

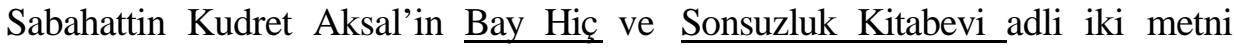
(1981) yukarida belirlenen çerçeve içinde romantik aydin karakterler içeren oyunlardir. Her iki oyun metninin de asal oyun kisileri, metne belli bir öz-gönderimsellik niteligi yükleyecek biçimde (potansiyel) yazarlar olarak tarif edilmislerdir.

ERKEK: Biliyor musunuz, her yazarin bir yerde sakli bir konusu vardir. Bütün is bulmaktir onu. Bir hamlede hem de. Onu buldu mu kurtulur ya da batar büsbütün. Benim konum da bu isik, bu pencereydi. Öykümü bunun üstüne kurdum.[...],

KADIN:Anladim: Siz, yazarsiniz![...]

ERKEK:Belki de yazarim. Ama ömrümde bir satir olsun yazmadim. Yazmadigima göre de bilinmez ki! Belki de yeryüzünün gelmis geçmis en büyük yazari benim! [B.H., s. 17]

\footnotetext{
${ }^{1}$ Andrew Bowie, Aesthetics and Subjectivity: From Kant to Nietzsche, 8Manchester:

Manchester University Press, 1993), s. 47.

${ }^{2}$ Oscar Walzel, German Romanticism (New York: Capricorn Books, 1966), s. 43.

${ }^{3}$ Ayni, s.44
} 
Benzer bir yaklasim Sonsuzluk Kitabevi oyunundaki Adam'da da görülür.Bir yaratici ya da üretici degildir Adam. Ama o da bütün bu büyük yazarlarin ölümsüzlügüne ulasmayi düslemektedir.

ADAM : Zamani dize getirenler! Ben de
sizdenim artik, sizden! Duyuyor
musunuz beni? Son halkasiyim yildiz
kervaninizin! (...) Büyük bir özlem
umulmayan bir basariyla erdi sona!
Yazildi adim tarihin altin yapragina!

[S.K., s. 95]

Bir tek kitap yazmamis Adam bütün insanliktan okurlarim diye söz eder. Bay Hiç'in kahramani Erkek, iyi bir yazar olma umudunu sakli tutmak için yazmamayi seçmistir, Coskun Ermis asla tamamlanamayan oyunlar yazip durur. Dogrudan ya da dolayli biçimde yazarlik atfedilmis bu üç oyun kisisi de yazarak yaratma eyleminden bir tür kusursuzluk bekledikleri, yaratinin "sinirsiz" olmasi gerektigini bildikleri ama ayni ölçüde de kendi sinirliliklarinin farkinda olmalari nedeniyle yazmamayi ya da yazdiklarinda bitirmemeyi seçerek bir öz-farkindalik gelistirirler. Üstelik içinde bulunduklari metinler baska bir "cesur" yazar tarafindan bitirilmisse de , o yazarlarin (S.Kudret Aksal, O.Atay) yarattiklari romantik kahramanlar ile kendi yazdiklari oyuna iliskin bir öz-farkindalik gelistirdikleri de söylenmelidir.

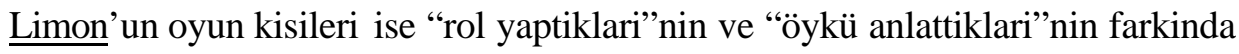
olduklarindan hem içinde bulunduklari metinle hem de daha önemlisi içinde bulunduklari gösteri ile bir farkindalik iliskisine girerler. Limon'da oyun kisileri içeri giren her yeni oyun kisisiyle birlikte kimlik degistirir ve bu anlamda kendileri için de, izleyici/okur için de taninmaz hale gelirler. Ancak bunu yaparken "rol" yaptiklarinin $\mathrm{da}$, islerin karistiginin da, hatta içinde bulunduklari dünyanin "oyun" dünyasi oldugunun da farkindadirlar. Kuskusuz bu öz-farkindalik niteliginin kaynaginin Alman romantizmi oldugunu söylemek Türkiye tiyatrosunun Bati tiyatrosundan önceki kaynagi olan geleneksel halk tiyatrosu geleneginin göstermeci ve öz-gönderimsel karakterini göz ardi etmek anlamina gelecektir. Ancak burada hedeflenen, bir kaynak arastirmasi degil, "romantik karakter" tanimina, bu oyun kisilerinin olus biçimleri ile ne denli uygun olduklarinin gösterilmesidir.

Söz konusu oyun kisileri sürekli olarak kendileri hakkinda düsünür, düsünce üretirler. Kim olduklarini saptamaya, ya da ifadelendirmeye çalisirlar.

NECIP:Necip Elbeyli. Avukat. [...] Dokuz vilayet, on dört ilçede avukatlik yapmis, 
bir yil önce bir seyyar köfte saticisinin sevgilisini biçaklamasini savunmus ve köftecinin intiharini müteakiben emekli olmus derken treni yürümedigi için hasbelkader bu aksam aranizda bulunan karacigeri mosmor bir insan. [L., s. 4243]

Coskun Ermis oyun yazmaya basladiktan sonra kendini daha farkli hissetmeye, buna bagli olarak da daha farkli tanimlamaya baslar.

COSKUN: Ne bileyim, sanki kendi istegimle emekliye ayrilmamisim. Sanki emekliye bile ayrilmamisim, sadece bana yeni bir görev verilmis. Peki neden bana verilmis bu görev? Çok akilli oldugum için mi? Çok bilgili oldugum için mi? [O.Y., s.46]

Coskun soyadina uygun olacak sekilde seçilmis biri oldugunu düsünmektedir. Aydin kendini kutsal bir konuma koymustur; siradan insanlardan tümüyle farklidir o. Bu kendini tanimlamak için yeni bir alandir. Üstelik romantik sanatçilarin kendilerini sik sik gündelik sinirliliklari, siradanliklari asmis kisiler olarak “dahi”lik sinifina yerlestirmelerinin, bu oyunda belirgin bir karsiligi vardir bu anlamda. Kerameti kendinden menkul bir "üstün olus hali", Coskun'un kimligini belirlemekte, bir yandan da yikimini hazirlamaktadir. Coskun yasama ait kimsenin bilmedigi bir bilgiye ya da gerçege sahip oldugunu düsünmektedir. Bu gerçek, kendinden yola çikarak, hakkinda soyutlamalar yaptigi Türk milleti ile ilgilidir.

COSKUN : Biz büyük bir milletiz Saffet.(...) Biz büyük bir milletiz derken, ayni zamanda demek istiyorum ki, evet ayni zamanda biz çocuk kalmis bir milletiz Saffet! Çünkü her seye çocuk gibi sevinir, çocuk gibi üzülürüz her seye. [O.Y., s. 48]

Kendi içinde yasayan kirilgan çocugu, ulusal kimlige tasir Coskun. Bu anlamda aydinin kendini tanimasi yasamsal bir önem tasir. Bireysel kimlik ile ulusal kimligin aynilastirilmasi, aydini bir kurban durumuna getirir. Kurbandir; çünkü tasidigi bütün zaaflar, ulusal kimlige ayni sekilde yansidigi için bunlardan bir an önce kurtulmak zorundadir. Böylesi saplantili bir düsünceyle, ulusal kimligi temize çikarmak için kendini kazimaya baslar Coskun. Can yakici dozda isletilen özelestiri mekanizmasi, giderek Coskun'un celladina dönüsecektir. Aydin'i artik ötekilerin günah keçisi yapmasina gerek kalmamistir. Oguz Atay'in aydini kendiliginden üstlenir bu misyonu. Kendi yetersizliklerinden ne kadar çok söz ederse, ülkesinin gelecegini o kadar güvence altina alacagini düsünür gibidir. 
sanki insanmisim gibi, yine buyrun bekleriz diyorum. [O.Y.,

\section{S. 53]}

Kendini bu denli yok sayma ancak bir tür kendini kurban etme duygusuyla açiklanabilir. Kuskusuz böyle bir duygu ayni sekilde hastalikli bir heyecani da beraberinde getirecektir. Tiyatrodan arkadaslari Servet, Emel ve Saffet'le birlikte içki içerken, sarhos olup, yaptigi konusma tiyatro edebiyatimizin aydin sorunu ile ilgili en önemli tiradi olarak anilacak gibidir.

COSKUN : Ey zavalli milletim dinle! Su anda hepimiz seni kurtarmak için toplanmis bulunuyoruz. Çünkü ey milletim, senin hakkinda, az gelismistir, geri kalmistir gibi söylentiler dolasiyor. (...) Neden böyle yapiyorsun? Neden az gelisiyorsun? Niçin bizden geri kaliyorsun? Bizler bu kadar çok gelisirken geri kaldigin için hiç utanmiyor musun? Hiç düsünmüyor musun ki, sen neden geri kaliyorsun diye düsünmek yüzünden, biz de istedigimiz kadar ilerleyemiyoruz. (...) Fakir fukaranin hayatini anlatan zengin yazarlarimiza gece klüplerinde içtikleri viskileri zehir oluyor. (...) Ey su fakir milletim! Aslinda seni anlatmiyoruz. Sefil ruhlarimizin korkak karanligini anlatiyoruz. Iste onun için sana yanasamiyoruz. Senin yaninda bir siginti gibi yasiyoruz. Hiç utanmiyor muyuz? Hiç utanmiyoruz. [O.Y., s. 51]

Memed Baydur'un oyununda da oyun kisilerinin kendilerini tanimlama biçimi hem bir farkindaliga hem de acimasizliga isaret eder. Oyun kisileri kendilerini tanimlarken, kendilerine benzer aydinlarin da tanimini yaparlar.

ENGIN : Hep bir seyler soran, hiç cevap vermeyen, biraz üstüne gidildi mi susup gülümseyen, her seyi ciddiye alirken alay edebilmenin sirinligine siginan, hosgörüsüz bir hosgörü avukati.... [L., s. 101]

Yasamin bogdugu aydinlar kendilerini ifade etmek ama öncelikle tanimlamak ihtiyaci içindedirler. Ancak hemen hepsi için kendini tanimlamak bir sorundur. Kendilerine tanimlamaya iliskin her denemelerinde, hem sonucun, hem de sürecin farkinda olarak baslarlar ise. Ancak bu oyun kisilerinin sürekli kendileri hakkinda söz üretmeleri, kimliklerini zaman zaman hedefleriyle zaman zaman varoluslari ile 
açiklamaya çalismalari onlarin konusmalarinin kendi üstüne kivrilan, hep kendine gönderen niteligine isaret eder. $\mathrm{Bu}$ nitelikleri ile özfarkindaligi içerik ve nitelik düzeyinde barindirirlar. Özfarkindaliga sahip romantik oyun kisilerinin içinde bulunduklari metinlerde, oyun içinde oyun, oyun içinde rol, oyun içinde gösteri, oyun içinde anlati gibi tekniklerle, ayni stratejinin oyunun yapisina da geçmesi saglanmistir.

\section{Romantik oyun}

Romantik "kahramanlar"in bilenmis farkindaliklari, gündelik yasam içinde "herkes" gibi yasamalarini imkans iz hale getirerek onlarin an' dan kaçmalarini, zaman'i asmalarini neredeyse zorunlu kilar. Oyun, hem zamansal hem mekansal kurgusuyla, bu tür oyun kisileri için bir siginaktir.

Yabancilasmis ve sözcügün gerçek anlamiyla yalnizlasmis "Bay Hiç" için varolmanin belki de tek yolu oyun kurmak ya da bir oyunun içinde yasamaktir. Adam bunu yapar. Yillarca çok uzaktaki bir evin isigina bakar ve bu evde yasadigini varsaydigi kadina asik olur. Bir bekleme ya da ümit etme oyunudur oynadigi ve salt bu oyuna tutunarak yasayabileceginin farkindadir. Kadin'in evlenme teklifini bu düsünceyle reddeder ve tekrar, yalniz odasina kadinin isigina bakarak umut etme oyununa döner. Aydin, bir yasam boyu beklediginin, gerçeklestiginde ne denli ümit kirici olacaginin ve oyun bittiginde kendisi için de her seyin biteceginin farkindadir. Ugruna yasayabilecegi bir umudu ya da korumasi gereken bir degeri kalmadigi için, bunu kendisi icat etmek zorunda kalmaktadir. Bunu da zamani, uzakliklari ve genel anlamda uzami dönüstürerek yapar.

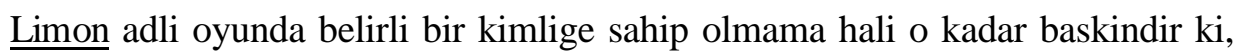
metindeki bütün anlamlarin önüne geçer. Kimse kendisi degildir ve bunu süreç içinde yasama tutunmanin biricik yolu haline getirmislerdir. Limon'un oyun kisileri için kendi kimlikleri dayanilmaz hale geldiginden baskalarini yasantilama oyununun rahatlaticiligina siginmislardir.

Oyun iki evin salonunda geçer. Muhsin'in garda tanisip eve getirdigi Necip disinda herkes birbirini tanimakta, ancak disardan eve gelen her insanla birlikte, evin içinde bulunanlarin birbiriyle iliskisi degismektedir. $\mathrm{Bu}$ degisim öyle hizli bir basdöndürücülük içinde ya sanir ki, sonuçta hem oyun kisileri hem de okur/izleyici kimin kim oldugunu unutacak duruma gelir. Aziz'in eski sevgilisi Asli dört yil sonra Necip Bey'in eve geldigi aksam sirilsiklam ve tükenmis, Aziz'i görmeye geldiginde, Necip Bey Asli'ya Aziz'in dayisi olarak tanistirilir. Komsulari yetmis yasindaki 
Berfinaz Hanim geldiginde mizansen yeniden degisecek, Necip Bey, Muhsin'in isyerinden arkadasi olarak tanitilacaktir. Asli bir uzak akrabadir ve Necip Bey Asli ile evlenmek istemektedir. Sonra Necip Bey aslinda bir avukat oldugunu söyleyip bu oyunu kesmelerini isteyince, Aziz onu sirkettekileri ve Asli üzerinde söz sahibi olan herkesi kandirmaya çalismakla suçlar. Arkadaslari Engin ve Sevda geldiginde ise Necip Bey bu kez de üç kitabi olan bir sair, Berfinaz Teyze de Aziz'in dadisi olarak tanistirilir. Degisimler kimi zaman da durumla degil, Baydur'un sahne yönergeleriyle yasanir:

[Roller yine degismistir simdi. Necip evsahibi ya da herseye hakim bir büyük gibidir artik. Asli esrarengiz, kimsenin tanimadigi bir konuktur. Muhsin sairdir, gizemli, bulutlu konusur. Ciddidir. Aziz alayci, "müstehzi" bir kuzen gibidir. Biraz simarik. Engin ile Sevda büyümüs evlatliklar gibidirler. Hem rahat, hem rahatsiz. Yalnizca Berfinaz, Berfinazligini korur. Onu degistirebilecek bir oyun yazari icat edilmemistir henüz. ] [L., s.65]

Burada oyun kisilerinin ortak karakteristikleri açisindan birarada incelenen oyunlarin aydin kahramanlarinin bir baska ortakliklari da dille olan iliskileridir. Geldikleri noktada söz, büyük ölçüde anlamini yitirmistir. Ama bu durum onlarin konusmamasina degil, dili kendi içinde tüketmelerine neden olmustur. Yaptiklari "okumalar" onlara sözle oyun kurma yetenegini saglamistir. Özellikle Limon ve Oyunlarla Yasayanlar oyunlarinda bu durum o denli öne çikar ki, fiili olarak kurulan oyunlardan bile daha önemlidir söz oyunlari. Kullandiklari dilin içerdigi ironi, onlari sistemin dislilerinden "koruyan" kalkanlardir. Alay ettikleri, içinde yasamak zorunda olduklaridir aslinda. Ve alay, özünde, hiç kimse için problemleri hafifletmemektedir.

MUHSIN: Küçük kusumun adi Baykus olmali. Onu havasizlikla uykusuzlukla, sigara ve alkol dumaniyla besleyecegiz.

AZIZ : Ali kusa viski al!..

MUHSIN: Ölümlerle, umutsuzlukla, nefretle, yalanla bü yütecegiz kusumuzu.

AZIZ : Baba, bana sustali çaki al.

MUHSIN: Acilardan süzülmüs, yine de iyimser bir kus ola cak bu. Yaralarini yalamayi reddeden, alçaklardan uçan, alçak gönüllü bir kus. [L., s.72]

Bilinen, çok sik yasanan ve bu nedenle de çok yakindan taninan, gündelik kliselerle ve siradan yasam biçimleriyle alay ederler. Ironinin temel hedefi, yine klise sözler ve tipki basim yasamlardir. 
ASLI: Karacigerinizin eli kalem tutsaydi da, gerçekleri kaydetseydi.

MUHSIN: Onu orta ikiye kadar okutabildik ablasi. Hep okuldan kaçar, sinemaya giderdi. Biraz daha büyüyünce, sinemadan kaçip meyhaneye gitmeye basladi. Bir tane karaciger tabii, sokaga atamazdik. Doktor olsun, mühendis olsun, memlekete faydali bir karaciger olsun istiyorduk. Okumadi. Ne dediysek tersine gitti. Anasi "bu karacigerin hali ne olacak?" diye az mi göz yasi döktui...Bir sinsi kaplan gibiydi deyyus.(...)Karacigerimin midesi bulaniyordu bu durumdan! Hiç bir seye inanmamaya baslamisti. Eh, insanlari sevmeye çalisan bir ciger için kolay degildi vaziyet!

AZIZ : Yeter! (...)

MUHSIN : (Oynar) Vallahi de olmaz, billahi de olmaz! Daha çok erken canim, söyle bir güzel tadini çikaralim...

SEVDA : Neyin tadini?

MUHSIN : Yabancilasmamizin?

AZIZ : Sonra asure yeriz. [L., s.75]

$\mathrm{Bu}$ yazida bir arada ele alinan metinlerin oyun kisilerinin benzerligini saglayan bir diger öge sözün kullanimi ve dille kurulan iliskidir. Dil, geleneksel düzenin anlasma aracidir ve toplumun diger kurumlarinda oldugu gibi yürürlükteki deger ölçütleri içinde kaliplasmistir. Burada incelenen aydinlar salt bu nedenle, sistemin devamliligini saglayan bir kurum olarak dile kuskuyla yaklasirlar. Sözcüklere atfedilen anlamlari alt üst ederek bu yapiyi parçalamaya çalisirlar. Bu tavir, yine bireysel bir içerik tasimaktadir. Gelinen noktada söz artik bir kendini anlatma araci olmaktan çikmis, bir silaha, ya da daha çok bir kalkana dönüsmüstür. Günlük yasamin- ya da daha genis bir kullanimla düzenin- yarattigi yilginlik ve korku, aydinlarda bir tür korunma güdüsü yaratmistir. Ama onlar ilkel degildir. Kendilerini koruyacak tüyleri ve pençeleri, uygarliga adim attiklarinda- bunu kendileri seçmislerdir- yerlerini salt düsünsel etkinliklere birakmis, dolayisiyla kendilerini savunabilecekleri son kaleye, söz'e siginmalarina neden olmustur. Ama bu sözde(n) kale yine sözle yikilabilmekte, bu nedenle esitler (aydinlar) arasindaki savaslar, oyunlarin çocuksu hainligini ve yikiciligini tasimaktadir. Gerçegin disinda görünen oyun alaninin bu denli öldürücü bir etkisi olmasi sasirtici oldugu denli, beklenilendir.

Bu kategoride ele alinan romantik oyun kisilerinin bir kismi Türkiyeli olmaya, Türkiye'de yasamaya yönelik sikintilari dile getirirler. Sorunlari sözellestirmek 
kuskusuz onlari çözmek demek degildir. Çünkü bu aydinlar söz konusu sorunlari neredeyse toplumsal bir sorun olma özelliklerinden indirgeyerek kendi özel sorunlari haline getirmislerdir. Memed Baydur'un Limon adli oyununda bir an açilan radyodan, kisa bir bölümü duyulan radyo tiyatrosu, içinde yasanilanin özeti gibidir. Sikiyönetimin yaptirimlari altinda yok olan kimliklerin, radyo oyunuyla alti çizilir.

RADYO : Bir halki ortadan kaldirmak için
hafizasini yok ederek ise baslanir,
anliyor musun?! Kitaplarini, tarihlerini,
kültürlerini yok ederler. Baskalari...
onlara baska kitaplar yazar, baska bir
kültür verir, baska bir tarih uydurur. Iste
George burada böyle yaziyor. Hüznün,
umutsuzlugun, unutusun dikte ettigi bir
ölüm kitabi bu. (...) Öylesine
pazarlanacak ki her sey, onlara
inanacagiz... [L., s.54-55]

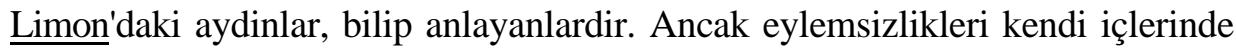
öyle büyük bir yargica dönüsmüstür ki, kendilerini yakici gerçeklikle yüzyüze getiren her durum, ya da olay, gelinen noktada, yok sayilmaya, görmezlikten, duymazliktan gelinmeye yazgilidir. Asiri duyarlik, duyarsizliga dönüsmüstür. Iki marjinal uç birbirinin kopyasidir. Siradan insandan her anlamda farkli gibi görünen bu aydin grup, radyo oyunundan rahatsiz olup kapatacaktir. Tipki ötekilerin yaptigi gibi... Dönüstürmeyen bilgi ve buna bagli gelisen duyarlik, romantik kahramanlari, ya da günlük gerçeklik içindeki karsiliklari ile romantik aydinlari 'sokaktaki adam'dan farklilastiramamakta, üstelik bir de 'ise yaramazligi’yla agir yükünü tasitmaktadir.

Oyun boyunca yapilan bütün söz oyunlari, ülkede nasil bir ideolojik yapilanmanin egemen oldugunu göstermektedir.

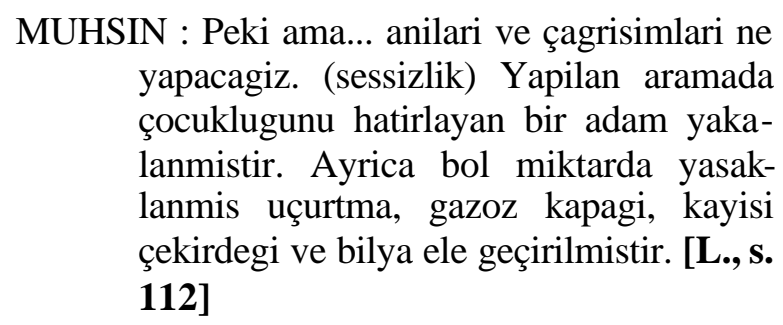

Yine oyun içinde Necip'in anlattigi oyuncular masali, inananlarin ölümü göze alarak savasmalarini ve binlerce kisiyi etkilemelerini, krala- mevcut düzene- karsi gelmelerini anlatmaktadir. Hersey bir oyun ola rak, oyun gibi baslamistir. Ama oyun gerçege dönüsecek, tehlikeli bir yokedicilik unsuru tasiyacaktir. Egemen olan, yeni ve degismeci olani istemeyecek ve hepsine zor kullanarak, yaptirimlar uygulayacaktir. Masalin bütün olumsuz ilerleyisine ragmen, tam kralin adamlari gelip bütün bu 
degisimleri baslatanlari öldürecegi sirada, masal beklenmedik bir sekilde kesilir. Necip, masalin kendisine de bu bölüme kadar anlatilmis oldugunu, sonra ne oldugunu , oyuncularin nereye kayboldugunu, kimsenin bilmedigini söyler. Bilinmezlik her seye karsin bir umut içermektedir. Bu umut bu ülkeyi degistirmeye inanan çocuklar için de sakli tutulmaktadir.

Her sey artik bir oyun kipiyle yasanir olmustur. Oyun aydinlar için yeni bir soluk alma alani haline gelmistir. Büyük yesil açik alanlardir oyunlar, sikici, bogucu, sikistirici kent yasaminin içinde. Gelinen noktada insanoglu gerçek bir parçalanma yasamaktadir. Schiller daha kendi zamaninda, 18. yüzyilin sonlarinda bile insanin yasadigi parçalanmaya isaret ederek, bunun büyük bir tehlike oldugunu söylemekteydi. Sorun insani bütün kilan baglarin kopmasiydi.

Yeni insanliga bu yarayi açan kültürün kendisi olmustur. Bir yanda genis denemeler ve belli düsünceler, bilimlerin birbirinden daha kesinlikle ayrilmasini gerektirince; öte yanda da devletlerin karisik mekanizmasi, insanlari ve isleri daha da kesinlikle ayirmayi zorunlu kilinca, insan dogasinin da iç bagi koptu. ${ }^{1}$

Schiller bu parçalanmanin tedavisine de isaret eder. Bu büyülü tedavi oyundur. Schiller'e göre, insan iki temel dürtüye sahiptir: duyusal dürtü ve biçim dürtüsü. Duyusal dürtü, insanin fizik varligindan, biçim dürtüsü ise ussal dogasindan kaynaklanir. Herbert Marcuse, uygarligin bu iki dürtüyü uzlastirmak yerine, duyusal olani ussal olana üstün kildigini söylemektedir. Oysa bu iki dürtüyü uzlastiracak bir üçüncü dürtü mevcuttur aslinda insan dogasinda. Iste bu Schiller'in tanimladigi oyun dürtüsüdür. Duyusal dürtü, degismenin olmasini, zamanin bir içerige sahip olmasini ister. Biçim dürtüsü zamani ortadan kaldirmayi, hiçbir degismenin olmamasini ister. Her iki dürtünün birlikte etkidigi oyun dürtüsü ise zamani zamanda ortadan kaldirmayi, olusu mutlak varlikla, degismeyi özdeslikle degistirmeyi amaçlamaktadir. Zamanin zamanda ortadan kaldirilmasi, bir tür "gibi yapmayi” gündeme getirmektedir. Sanki zaman geçmiyormus, hiç geçmemis gibi yapmayi... Bu simülasyon oyunun özünde vardir. Schiller, tek cümlesiyle bu konuda bütün söylenenleri özetler:

\footnotetext{
${ }^{1}$ Friedrich Schiller, Insanin Estetik Egitimi Üzerine Bir Dizi Mektup Çev.:Melahat Özgü (Istanbul: Milli Egitim Basimevi, 1990),s. 23.
} 
Insan sözcügün tam anlamiyla insan oldugu yerde yalnizca

oynar ve o, oyna digi yerde ancak tam insandir. ${ }^{1}$

Oyun kavramina ve Türkiye yazinina girisine Oguz Atay'la tarih düsmek olasidir. Bu tarihsel an kuskusuz bir raslanti degildir. Günlük yasam pratigi aydina böyle bir çikis önerecek hale gelmistir. Bu tarihten sonra pek çok yazar da ayni yoldan geçecek ve Oguz Atay'in oyun yolunda attigi ayak izlerini sürecektir. Artik gerçek tümüyle deri degistirmistir. Yeni yapisiyla bir önceki gerçekten daha gerçektir.

$\mathrm{Bu}$ romantik aydin oyun kahramanlarinin bir diger ortak paydasi zamanla kurduklari farkli iliskileridir. Oyun dürtüsünün zamansal içerigine uygun olacak sekilde zamanin zamanda ortadan kalkmasi gibi bir tutkuyla hareket ederler.

Oyunla yasama Oyunlarla Yasayanlar' in emekli tarih ögretmeni Coskun Ermis için tarihi oyunlar yazma ve tiyatro yasantisini gerçek bir yasantiya dönüstürme oyunudur. Limon 'da bütün oyun kisileri (Muhsin, Aziz, Necip, Asli, Berfinaz, Engin, Sevda) "içinde bulunduklari iliski agini ve durumu degistirme oyununu", Sonsuzluk

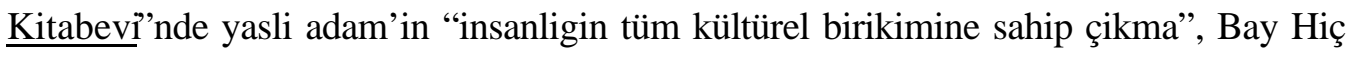
ise "arama ve bekleme" oyununu oynamaktadir. Oyun üzerine kurulmus bir düzen hiç kuskusuz ütopiktir ve içinde yasanan zamana askin oldugu için de romantiktir. Özgürlükle es anlamli sayilabilecek oyun, düzene yayildiginda salt bireysel degil, toplumsal bir kurtulusu da vadetmektedir.

Oyunun temel ilke olarak alindigi bir toplum düzeni, insanlar üzerinde baskici olmayan bir kültürü yaratmakla insanin özgürlügünü gerçeklestirmis olacaktir. Marcuse'ün Schiller'e dayanarak gelistirdigi oyun kuraminda, yalniz sanat degil, tüm insan etkinlikleri, örnegin çalisma bile bir oyun olarak düsünülür. Bu kuram insanin bütün zorluklarinin ortadan kalkacagi varsayilan ütopik bir toplum için öngörülür.2

Kaynagini öznellikten alan oyun dünyasi, bir özgürlük vaadi gibi görünmektedir ancak, bireysel düzlemde hayata karsi bir tavir olarak nitelendirildiginde oyun,

\footnotetext{
${ }^{1}$ Ö. Naci Soykan. "Sanatin Kaynagi Sorunu: Oyun ve Dans" Felsefe Dünyasi, sayi:2, Aralik 1991, s.44-45.

${ }^{2}$ Besim F. Dellaloglu. Frankfurt Okulu'nda Sanat ve Toplum. (Istanbul: Baglam Yayinlari, 1995), s. 62.
} 
bir anlamda düsünen insanin, toplumsal gerçeklere ters düstügü için basvurdugu bir kaçis yoludur; iç dünyasina siginisidir. ${ }^{1}$

Çagdas oyun metinlerinde izi sürülen "romantik kahraman"in, asal niteliklerini, genelde bati romantizminden, özelde Alman romantizminden devralmis oldugunu saptamak mümkün görünmektedir. Ancak bu noktada, "yerli" romantik kahramanlari içeren oyunlarin pek çogunda Türkiye'li olmaktan, siyasal/toplumsal arkaplandan özel olarak söz edildigi görülmekte; an'dan kaçisin gerekçesini, felsefi bir akil yürütmeden çok içinde yasanilan olumsuz "toplumsal" kosullarin farkinda olmak olusturmaktadir. Dolayisiyla on sekizinci yüzyil romantik oyunlarinda hemen hiç verilmeyen siyasal ortam, yirminci yüzyilda Türkiye'de yaratilan romantik oyun kisileri için asal belirleyici düzeyindedir. Türkiye'de çagdas oyun yazarliginin önemli isimleri Oguz Atay, Sabahattin Kudret Aksal ve Memed Baydur'un oyunlarinda yarattiklari kahramanlara verdikleri "entelektüel" olma niteligi, bu oyun kisilerini, Bati tiyatrosu içinde ve yaklasik iki yüz yil önce yaratilmis benzerlerinden ayirmakta, Avrupali "romantik kahraman" olusumu, sinir ve zaman "asarken”, ona kendine özgü niteligini veren cesaret, gözüpeklik, yurtseverlik, coskunluk gibi niteliklerinde radikal degisimler olmustur. Avrupali "romantiklerin" nedeni bir çirpida özetlenemeyecek genel melankolik halleri, Türkiye'li "romantikler"de, yerini, neden çekildigi asikar olan bir sürekli aciya birakmistir.

\section{KAYNAKÇA}

.Bakhtin,M.M. The Dialogic Imagination: Four Essays. Ed.: Michael Holquist, Çev..: Carly

Emerson ve Michael Holquist Austin: University of Texas Press, 1981.

Aksal, Sabahattin Kudret. Bay Hiç Istanbul: Cem Yayinevi, 1991.

, Sonsuzluk Kitabevi Istanbul: Cem Yayinevi, 1991.

Atay,Oguz. Oyunlarla Yasayanlar, Istanbul: Iletisimm Yayinlari, 1993.

, Tutunamayanlar Istanbul: Iletisim Yayinlari, 1984.

Baydur, Memed. Limon Istanbul: Boyut Yayinlari, 1993.

Bowie, Andrew. Aesthetics and Subjectivity: From Kant to Nietzsche, Manchester: Manchester University Press, 1993.

Dellaloglu, Besim F. Frankfurt Okulu'nda Sanat ve Toplum. Istanbul: Baglam Yayinlari, 1995 Ecevit,Yildiz. Oguz Atay'da Aydin Olgusu Istanbul: Ara Yayincilik, 1989.

Gürbilek, Nurdan.. Yer Degistiren Gölge. Istanbul: Metis Yayinlari, 1995.

Kaufmann, Walter. Dostoyevski'den Sartre'a Varolusçuluk, Çev.: Aksit Göktürk Istanbul:: de Yayinevi, 1965.

${ }^{1}$ Yildiz Ecevit, Oguz Atay'da Aydin Olgusu (Istanbul: Ara Yayincilik, 1989), s. 37. 
Marcuse, Herbert. Eros ve Uygarlik, Çev.: S. Çagan Istanbul: May Yayinlari, 1968.

Oktay, Ahmet. Zamani Sorgulamak Istanbul: Remzi Kitabevi, 1991.

Schiller, Friedrich. Insanin Estetik Egitimi Üzerine Bir Dizi Mektup Çev..:Melahat Özgü

Istanbul: Milli Egitim Basimevi, 1990

Soykan, Ö. Naci. "Sanatin Kaynagi Sorunu: Oyun ve Dans"Felsefe Dünyasi, sayi:2, Aralik 1991.

Walzel, Oscar. German RomanticismNew York: Capricorn Books, 1966. 